\title{
MENGULAS PENYEBAB BANJIR DI WILAYAH DKI JAKARTA DARI SUDUT PANDANG GEOLOGI, GEOMORFOLOGI DAN MORFOMETRI SUNGAI
}

\author{
Budi Harsoyo
}

\begin{abstract}
Intisari
Banjir sudah tidak dapat dipisahkan dari kehidupan masyarakat yang tinggal di wilayah DKI Jakarta dan sekitarnya. Setiap kali musim hujan tiba, Kota Jakarta seolah tidak pernah terlepas dari pemberitaan seputar kejadian banjir yang melanda wilayahnya. Tulisan ini mengulas faktor-faktor penyebab banjir di wilayah DKI Jakarta, terutama dari sudut pandang geologi, geomorfologi dan morfometri sungai yang mengalir dan melintasi wilayah DKI Jakarta. Penulis mengumpulkan bahan pustaka dari berbagai sumber untuk memberikan ulasan dan sebuah kesimpulan bahwa secara kodrat, Jakarta memang merupakan daerah banjir sehingga bagaimana pun, kejadian banjir akan sangat sulit untuk dihilangkan dari wilayah DKI Jakarta.
\end{abstract}

\begin{abstract}
Flood cannot be separated from the life of the people around DKI Jakarta. Everytime rainy season comes, Jakarta was never be apart from the news about flood incidence hit this region. This paper reviews some factors causing the floods especially from geological, geomorphological, and morphometrical point of view of the rivers flow across DKI Jakarta. The author gathered materials from various sources to give an analysis and conclusion that Jakarta, by nature, is flooded area so flood event will be very difficult to be removed.
\end{abstract}

Kata Kunci : banjir, musim hujan, sungai

\section{Pendahuluan}

Pasca kejadian banjir besar pada tanggal 17 Januari 2013 yang menggenangi hampir seluruh wilayah DKI Jakarta dan sempat melumpuhkan segala aktivitas di ibukota, Badan Pengkajian dan Penerapan Teknologi (BPPT) bekerjasama dengan Badan Nasional Penanggulangan Bencana (BNPB) melakukan upaya antisipatif dengan menyelenggarakan Operasi Teknologi Modifikasi Cuaca (TMC) Untuk Redistribusi Curah Hujan Dalam Rangka Tanggap Darurat Banjir di Provinsi DKI Jakarta dan Sekitarnya. Dari hasil evaluasi, pelaksanaan TMC di wilayah DKI Jakarta dan sekitarnya yang berlangsung selama 33 hari (26 Januari - 27 Februari 2013) dinilai cukup berhasil mengurangi intensitas curah hujan sebagai penyebab banjir di wilayah DKI Jakarta dan sekitarnya. Berdasarkan hasil analisis data curah hujan selama periode kegiatan TMC, curah hujan di wilayah DKI Jakarta dan sekitarnya berkurang sekitar 38,64\% terhadap nilai curah hujan historisnya pada periode waktu yang sama (sumber : Laporan Kegiatan Pemanfaatan Teknologi Modifikasi Cuaca Untuk
Redistribusi Curah Hujan Dalam Rangka Tanggap Darurat Banjir di Provinsi DKI Jakarta dan Sekitarnya Tahun 2013, UPT Hujan Buatan BPPT, 2013).

Terlepas dari adanya tanggapan pro dan kontra dari masyarakat luas terkait pelaksanaan TMC untuk redistribusi curah hujan di wilayah DKI Jakarta dan sekitarnya, satu hal yang bisa diambil positifnya adalah bahwa teknologi ini mulai dipercaya oleh Pemerintah Daerah Provinsi DKI Jakarta sebagai bagian dari upaya aksi mitigasi bencana banjir di wilayah DKI Jakarta dan sekitarnya yang hampir selalu terjadi setiap tahun saat musim hujan tiba. Namun demikian perlu dipahami bersama bahwa upaya TMC dalam skema mitigasi bencana banjir di wilayah DKI Jakarta dan sekitarnya lebih bersifat "mengurangi resiko", bukan berarti "menghilangkan resiko" banjir, karena bagaimana pun fenomena banjir sudah tidak dapat dipisahkan dengan wilayah DKI Jakarta.

Sejarah Banjir Jakarta 
Sejarah mencatat banjir sudah mengakrabi Jakarta sejak awal pendirian kota ini oleh Pemerintah Hindia Belanda. Awalnya pada tahun 1619, Jan Pieterszoon Coen meminta Simon Stevin merancang sebuah kota di muara Sungai Ciliwung yang sering kebanjiran sebagaimana Kota Amsterdam di Belanda. Kota Batavia (sekarang menjadi Jakarta) dibangun dengan dikelilingi parit-parit, tembok kota, lengkap dengan kanal. Dengan kanal-kanal itu, Coen berharap bisa mengatasi banjir, sekaligus menciptakan sebuah kota yang menjadi lalu lintas pelayaran, sebagaimana kota-kota di Belanda. Sungai Ciliwung yang berkelok-kelok dialihkan dan digantikan sebuah terusan lurus yang membelah Kota Batavia menjadi dua bagian. Namun demikian, sistem kanal yang telah dibangun ternyata tidak mampu mengatasi banjir besar yang melanda Batavia pada tahun 1932 dan 1933. Contoh bangunan kanal dan pintu air peninggalan jaman Belanda yang dahulu dibangun untuk mengatasi permasalahan banjir di wilayah Jakarta dan masih ada hingga kini antara lain Kanal Banjir Kalimalang, Pintu Air Matraman, dan Pintu Air Karet (sumber : Kompas, 18 Januari 2013).

\section{Geologi Jakarta}

Menurut ahli geologi Lembaga IImu Pengetahuan Indonesia, Jan Sopaheluwakan, banjir Jakarta tidak akan dapat diselesaikan dengan sistem kanal karena secara geologis Jakarta sebenarnya merupakan cekungan banjir. Sebaliknya, kawasan utara Jakarta (sekitar Ancol dan Teluk Jakarta) mengalami pengangkatan karena proses tektonik. Oleh karena itu, air dari 13 sungai yang bermuara di Teluk Jakarta tidak bisa mengalir lancar ke laut dan kerap terjebak di cekungan besar Jakarta. Cekungan ini terbentuk dari tanah sedimen muda sangat tebal tetapi belum terkonsolidasi. Akibatnya, secara geologis, tanah di Jakarta perlahan mengalami penurunan. Penurunan permukaan tanah secara alami ini semakin diperparah dengan pengambilan air tanah secara besar-besaran oleh masyarakat Jakarta. Penurunan permukaan tanah di Jakarta bervariasi di beberapa tempat, dengan laju antara 4-20 sentimeter per tahun (Kompas, 18 Januari 2013).

Dalam buku The Geology of Indonesia, Van Bemellen (1977) menunjukkan bahwa Kota Jakarta tersusun atas endapan pantai dan endapan volkanik, seperti terlihat dalam Gambar 1. Proses pembentukan endapan pantai yang secara stratigrafi terhampar di bawah endapan volkanik tersebut salah satunya melalui mekanisme banjir. Sederhananya seperti terlihat dalam Gambar 2, aliran sungai yang menggerus lapisan endapan volkanik akan memperlihatkan endapan pantai yang berada di bawahnya.

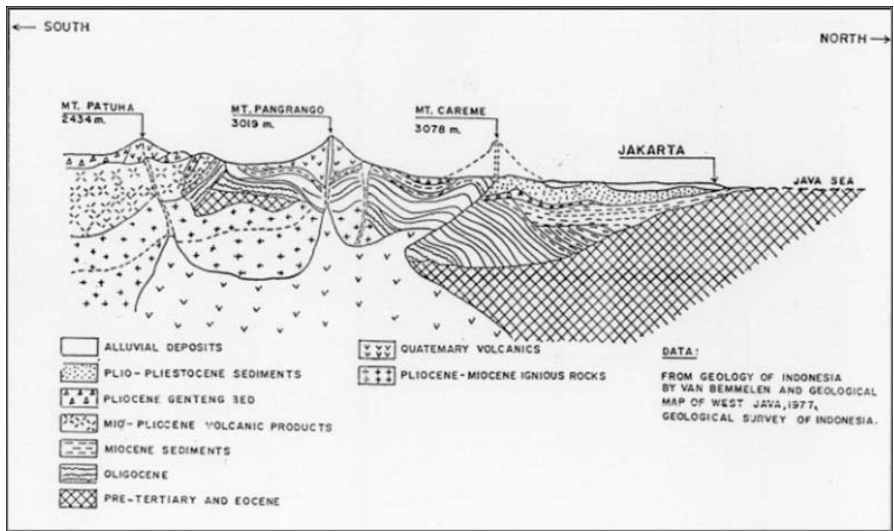

Gambar 1. Penampang Geologi Wilayah Jakarta

(Sumber : The Geology of Indonesia, Van Bemellen, 1977; dikutip dari Dongeng Geologi; http://rovicky.wordpress.com/2007/02/02/whalllah-banjir/)

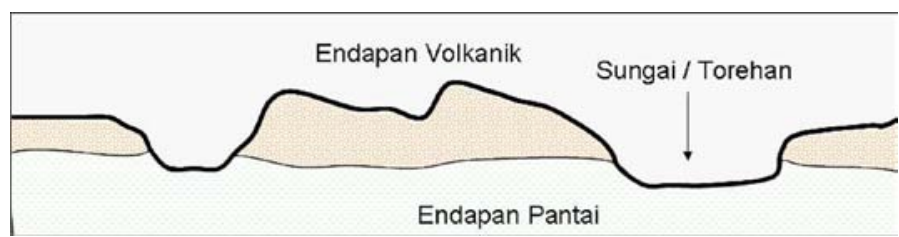

Gambar 2. Sketsa sungai yang menggerus endapan volkanik 
(Sumber : Dongeng Geologi; http://rovicky.wordpress.com/2007/02/02/whalllah-banjir/)

Proses alami penggerusan endapan volkanik oleh aliran sungai terlihat jelas dalam Peta Geologi Jakarta yang tergambar pada Gambar 3. Dari potongan peta geologi tersebut terlihat bahwa di sepanjang aliran sungai, jenis batuannya merupakan endapan pantai, bukan endapan volkanik sebagaimana mayoritas batuan penyusun wilayah Jakarta bagian selatan. Dari peta ini juga terlihat bahwa wilayah Jakarta bagian utara tersusun oleh material endapan pantai dan sungai. Hal ini menunjukkan bahwa sejak dulu, wilayah Jakarta memang sudah merupakan daerah banjir.

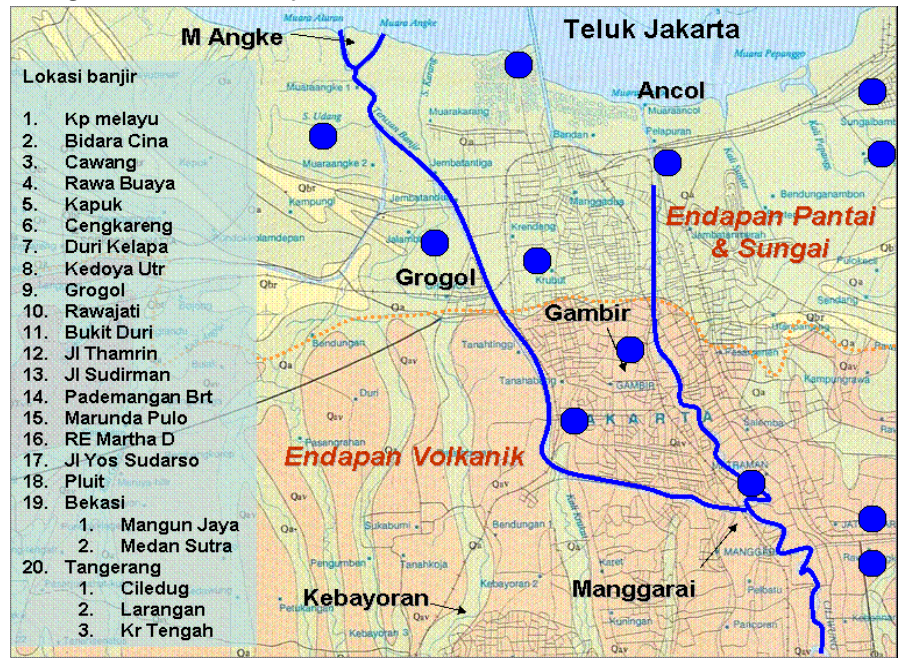

Gambar 3. Peta Geologi sebagian wilayah Jakarta

(Sumber : Dongeng Geologi; http://rovicky.wordpress.com/2007/02/02/whalllah-banjir/)

\section{Geomorfologi Jakarta}

Selain secara geologi Jakarta merupakan daerah cekungan, secara geomorfologi Jakarta juga merupakan dataran banjir (flood plain). Dataran banjir merupakan daerah yang terbentuk akibat proses sedimentasi saat terjadi banjir. Dataran banjir pada umumnya berada di sekitar aliran sungai yang berkelok-kelok (meandering) atau pada titik pertemuan anak sungai dengan aliran sungai utama, seperti tergambar dalam Gambar 4. Dengan keberadaan 13 aliran sungai yang melintasi Kota Jakarta, maka memang cukup banyak dataran banjir yang tersebar di wilayah DKI Jakarta. Oleh karena itu, cukup bisa dimaklumi bahwa potensi banjir di wilayah DKI Jakarta memang sangat tinggi. Sket ke-13 aliran sungai yang melintasi Kota Jakarta tergambar dalam Gambar 5.

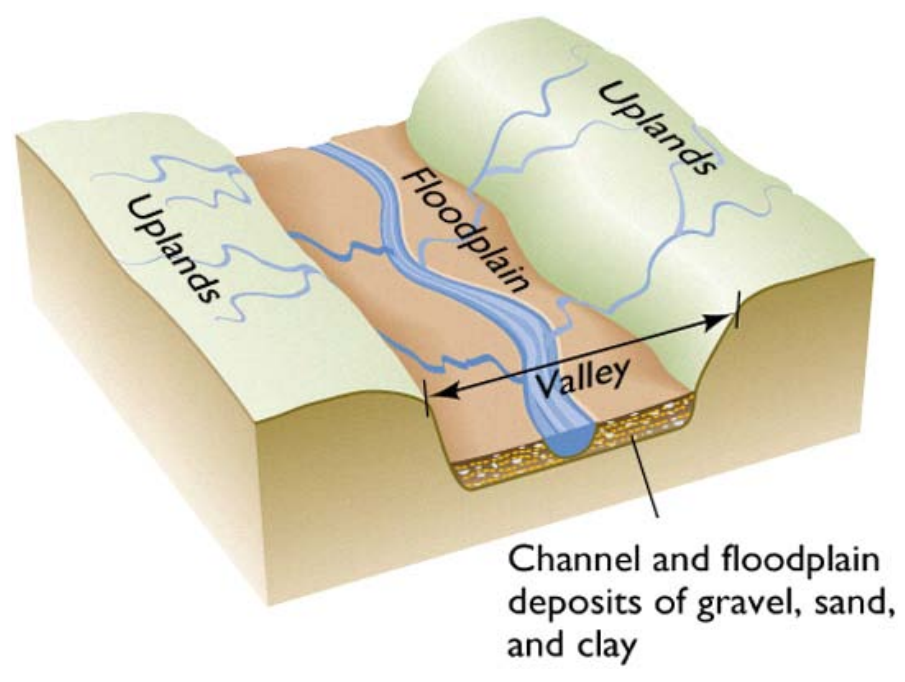


Gambar 4. Blok diagram Dataran Banjir dan meander sungai (sumber: http://floodsworld.blogspot.com/)

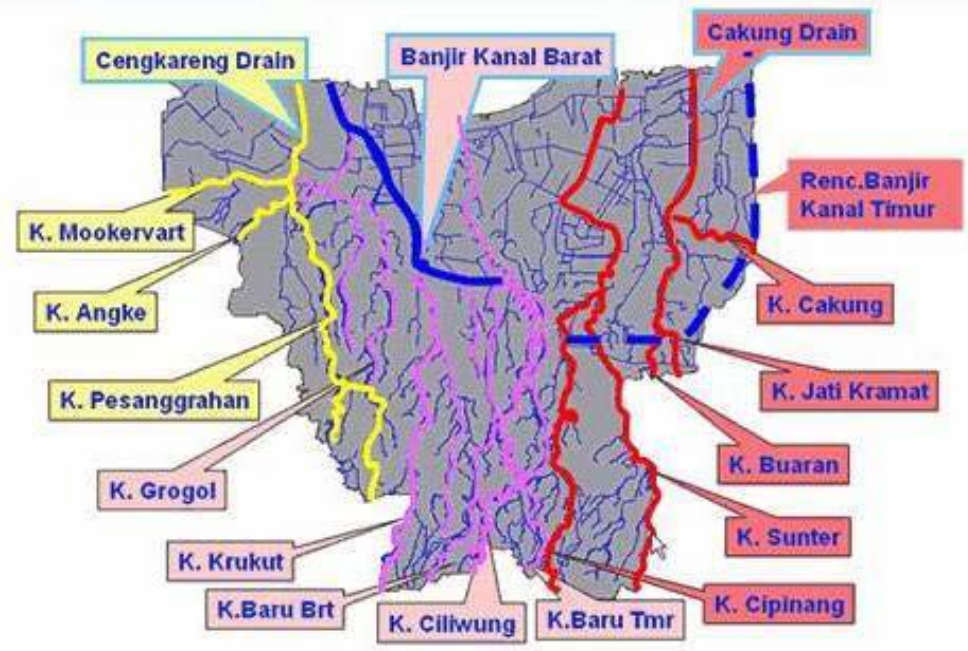

Gambar 5. Sket 13 aliran sungai yang melintasi Kota Jakarta (sumber : http://bebasbanjir2025.wordpress.com/konsep-pemerintah/bappeda-dki-jakarta/)

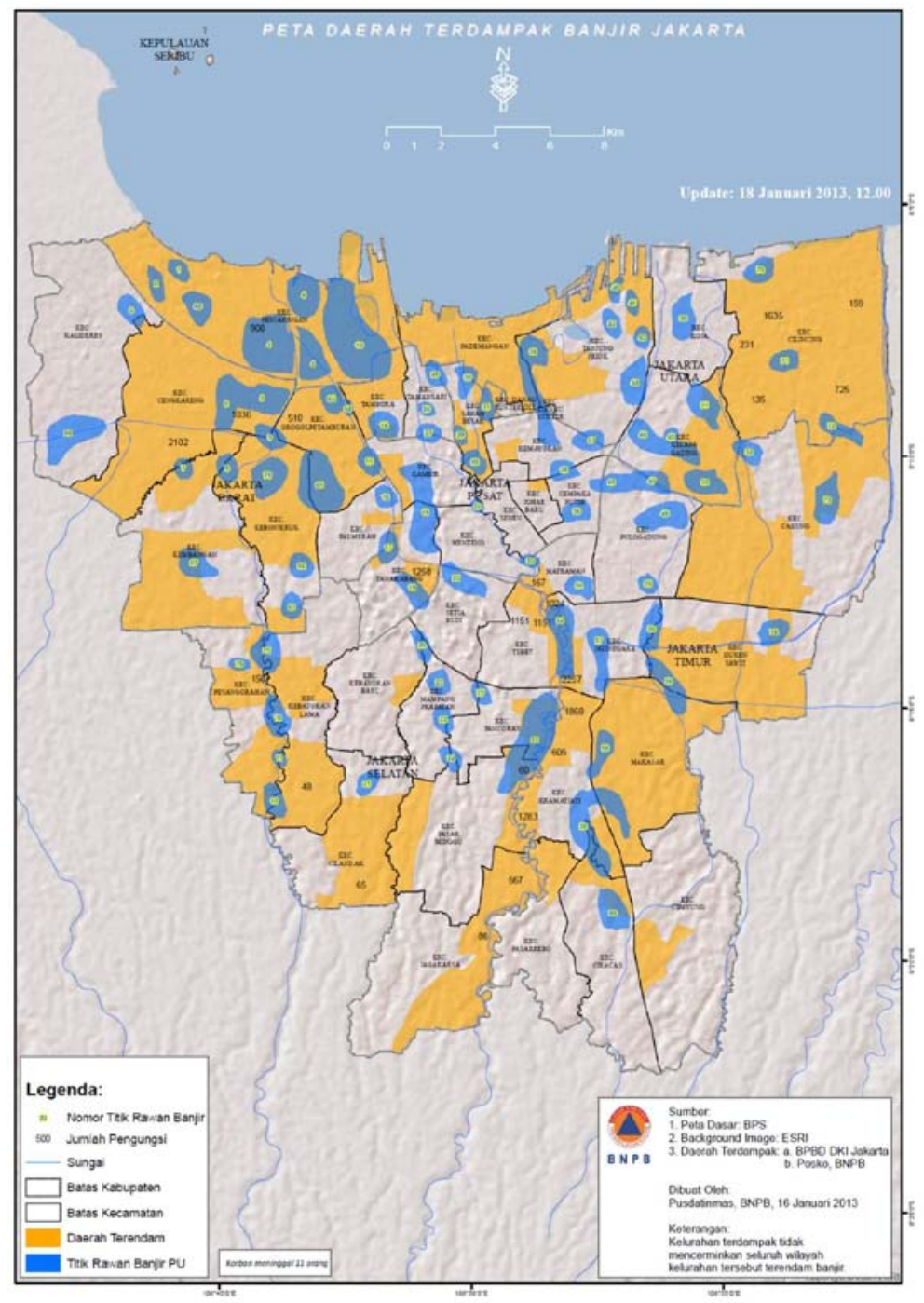

Gambar 6. Peta Daerah Terdampak Banjir Jakarta tanggal 17 Januari 2013 (sumber : BNPB, diambil dari http://rovicky.wordpress.com/2013/01/18/banjir-jakarta-2013-1-peta-terdampak/) 
Gambar 6 memperlihatkan Peta Daerah Genangan dari kejadian banjir di wilayah DKI Jakarta pada tanggal 17 Januari 2013 yang dibuat oleh BNPB. Area berwarna orange adalah daerah yang terendam banjir, sementara area berwarna biru merupakan lokasi-lokasi titik rawan banjir yang diidentikasi dari historis kejadian banjir tahun-tahun sebelumnya. Dari peta tersebut terlihat bahwa lokasi daerah genangan yang notabene merupakan dataran banjir berada tidak jauh dengan aliran sungai yang berpola meandering atau pada titik pertemuan dua aliran sungai. Jadi, karena secara teori lokasi dataran banjir selalu berasosiasi dengan keberadaan aliran sungai yang berpola meandering, maka dengan banyaknya aliran sungai yang melintas di Jakarta tentu sudah menjadi konsekuensi logis jika wilayah DKI Jakarta sangat rawan akan potensi banjir.

\section{Morfometri Sungai di Wilayah DKI Jakarta}

Dari ke-13 aliran sungai yang melintasi Kota Jakarta, Sungai Ciliwung merupakan sungai yang paling besar kontribusinya terhadap potensi kejadian banjir di wilayah DKI Jakarta. Menurut NEDECO (1973), luas Daerah Aliran Sungai (DAS) Ciliwung sekitar $347 \mathrm{~km}^{2}$, terluas dibandingkan DAS lainnya. Panjang aliran Sungai Ciliwung mulai dari hulunya di daerah Gunung Gede - Pangrango (Kabupaten Bogor) hingga daerah hilirnya di daerah Pluit (Jakarta
Utara) sepanjang $117 \mathrm{~km}$, terpanjang dibandingkan aliran sungai lainnya. Selain itu, aliran Sungai Ciliwung di Kota Jakarta melintasi banyak perkampungan, permukiman padat penduduk dan permukiman kumuh. Aliran sungai ini pula yang aksesnya langsung menuju jantung Kota Jakarta dimana lokasi Pusat Pemerintahan berada, sehingga jika sungai ini meluap dan membanjiri Jakarta dalam waktu yang relatif lama maka dampaknya dapat melumpuhkan segala aktivitas ekonomi, sosial maupun aktivitas pemerintahan yang terpusat di Kota Jakarta.

Selain Sungai Ciliwung, Sungai Angke dan Sungai Pesanggrahan juga memberikan kontribusi yang cukup signifikan terhadap potensi banjir di wilayah DKI Jakarta. DAS Angke memiliki luas sekitar $263 \mathrm{~km}^{2}$ dengan panjang aliran sungai utama $100 \mathrm{~km}$, sementara DAS Pesanggrahan memiliki luas $110 \mathrm{~km}^{2}$ dengan panjang aliran sungai utama $83 \mathrm{~km}$. Sungai Angke berhulu di daerah Semplak (Kabupaten Bogor), mengalir ke wilayah Tangerang Selatan, Kota Tangerang, Jakarta Barat dan bermuara di Muara Angke (Jakarta Utara), sedangkan Sungai Pesanggrahan berhulu di daerah Tanah Sereal (Kabupaten Bogor), mengalir melalui Kota Depok, wilayah Jakarta Selatan, Kota Tangerang, wilayah Jakarta Barat untuk kemudian bergabung dengan aliran Sungai Angke dan juga bermuara di Muara Angke (Jakarta Utara).

Tabel 1. Morfometri Aliran Sungai di Wilayah DKI Jakarta

\begin{tabular}{|l|r|r|r|r|}
\hline \multicolumn{1}{|c|}{$\begin{array}{c}\text { Sungai } \\
\text { (DAS) }\end{array}$} & $\begin{array}{r}\text { Luas } \\
\left(\mathbf{k m}^{2} \mathbf{)}\right.\end{array}$ & $\begin{array}{c}\text { Panjang } \\
\text { Sungai } \\
\text { Utama } \\
\mathbf{( k m )}\end{array}$ & $\begin{array}{c}\text { Elevasi } \\
\text { Tertinggi } \\
\mathbf{( m )}\end{array}$ & $\begin{array}{c}\text { Elevasi } \\
\text { Terendah } \\
\mathbf{( m )}\end{array}$ \\
\hline Cakung & 55 & 33 & 6 & 90 \\
\hline Buaran & 30 & 23 & 9 & 45 \\
\hline Sunter & 73 & 40 & 12 & 122 \\
\hline Cipinang & 48 & 36 & 12 & 107 \\
\hline Ciliwung & 347 & 117 & 8 & 2908 \\
\hline Krukut & 98 & 37 & 7 & 117 \\
\hline Grogol & 33 & 27 & 29 & 100 \\
\hline Pesanggrahan & 110 & 83 & 3 & 205 \\
\hline Angke & 263 & 100 & 3 & 220 \\
\hline
\end{tabular}

Jadi memang benar jika sumber banjir di wilayah DKI Jakarta berasal dari aliran ke-13 sungai tersebut. Namun jika ingin mengantisipasi permasalahan banjir di wilayah DKI Jakarta, cakupannya tidak hanya sebatas wilayah administrasi Provinsi DKI Jakarta saja, 
namun harus bersifat lintas wilayah dan lintas sektoral. Untuk keperluan antisipasi banjir di wilayah DKI Jakarta melalui upaya redistribusi curah hujan dengan memanfaatkan Teknologi Modifikasi Cuaca (TMC), daerah targetnya harus mencakup seluruh catchment area dari 13 sungai yang mengalir ke wilayah DKI Jakarta, mulai dari hulu hingga ke hilir. Dari hasil analisis pola aliran sungai dengan menggunakan Sistem Informasi Geografis (SIG), daerah target TMC yang didelineasi berdasarkan gabungan Daerah Aliran Sungai (DAS) dari beberapa aliran sungai yang melintas di wilayah DKI Jakarta tersebut tergambar dalam Gambar 7.

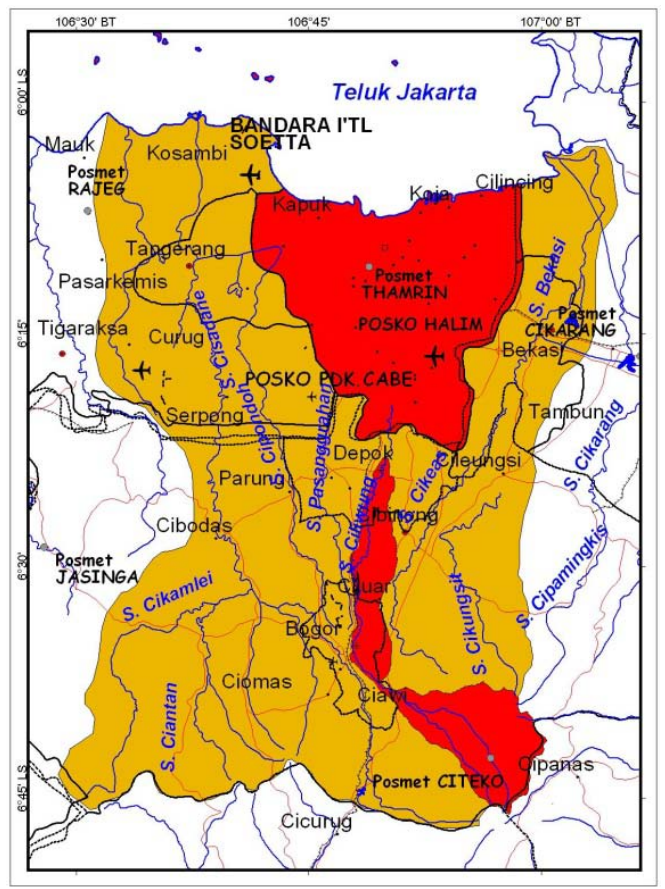

Gambar 7. Daerah target upaya redistibusi curah hujan di wilayah DKI Jakarta dengan TMC; Catchment area aliran sungai yang melintas di wilayah DKI Jakarta (Sumber : Hasil analisis GIS)

Dari peta dalam Gambar 7 tersebut, daerah yang diarsir warna merah (wilayah administrasi Provinsi DKI Jakarta dan DAS Ciliwung) merupakan daerah target primer yang perlu dilindungi dari curah hujan dengan intensitas tinggi. Sebisa mungkin curah hujan yang jatuh di daerah target primer tersebut diusahakan tidak terlalu tinggi, apalagi dalam durasi yang cukup panjang. Jika curah hujan dengan intensitas tinggi terjadi di atas wilayah DKI Jakarta secara langsung, maka akan berpotensi langsung menimbulkan genangan air di beberapa lokasi seperti yang tergambar dalam Gambar 6. Demikian pula jika curah hujan tinggi terjadi di daerah Puncak (Bogor) yang menjadi hulu DAS Ciliwung, karena berpotensi menimbulkan banjir kiriman yang akan sampai ke pusat kota yang menjadi jantung segala aktivitas di wilayah DKI Jakarta dalam beberapa jam berikutnya.

Daerah target sekunder (arsiran berwarna orange dalam peta) merupakan cakupan dari DAS lain yang juga alirannya bermuara ke wilayah perairan di Teluk Jakarta. Meski demikian bukan berarti jika curah hujan yang terjadi pada bagian hulu sungai lainnya (selain Sungai Ciliwung) tidak berpotensi membawa banjir kiriman ke wilayah DKI Jakarta, namun dengan alasan dari aspek morfometri sungai dan akses aliran sungainya terhadap potensi dampak banjir di wilayah DKI Jakarta seperti yang sudah diuraikan sebelumnya maka curah hujan yang jatuh di wilayah target sekunder ini masih relatif lebih aman dibandingkan dengan jika jatuh di daerah target primer. Total luas daerah target operasional TMC seperti tergambar dalam Gambar 7 adalah seluas $3.904,37 \mathrm{~km}^{2}$ atau hampir sekitar 6 x luas wilayah administrasi Provinsi DKI Jakarta yang seluas $674,68 \mathrm{~km}^{2}$. 


\section{Penutup}

Pada bagian akhir tulisan ini, Penulis ingin menyimpulkan bahwa secara geologi dan geomorfologi wilayah DKI Jakarta sendiri sejak dulu memang sudah merupakan daerah banjir. Selain itu, dengan keberadaan morfometri dari ke-13 aliran sungai yang melintasi wilayah DKI Jakarta juga menjadi akses bagi aliran air permukaan (direct runoff) yang bersumber dari curah hujan di daerah hulu untuk masuk ke wilayah DKI Jakarta. Jadi, memang sudah kodratnya bahwa wilayah DKI Jakarta adalah merupakan daerah banjir. Pembangunan infrastruktur banjir dan upaya konservasi lingkungan untuk memperbaiki kondisi catchment area yang telah rusak dan jauh berkurang luasannya hanyalah merupakan langkah-langkah untuk mengurangi potensi resiko bencana banjir, bukan bersifat menghilangkan resiko banjir menjadi tidak ada sama sekali. Singkatnya, jika seandainya infrastuktur dan kondisi lingkungan catchment area dalam kualitas yang baik saja masih akan selalu ada potensi resiko banjir di wilayah DKI Jakarta, lantas bagaimana jika keduanya tidak berfungsi dengan baik? Akibatnya seperti inilah yang terjadi sekarang. Bencana banjir semakin akrab dengan kehidupan masyarakat Jakarta dan sekitarnya setiap kali musim hujan tiba.

\section{Daftar Pustaka}

Dongeng Banjir. 2007. Whallah Banjir. Situs http://rovicky.wordpress.com/2007/02/02 /whalllah-banjir/
Dongeng Banjir. 2013. Banjir Jakarta 2013 : 1. Peta terdampak.Situs: http://rovicky.wordpress.com/2013/01/18/banjir-jakarta2013-1-peta-terdampak/

FLOODS-Can it mitigate?. 2012. What is Flood?Situs:

http://floodsworld.blogspot.com/

Harian Kompas. 2013. Dataran Banjir Yang Kebanjiran. Edisi 18 Januari 2013.

Nedeco. 1973. Masterplan for Drainage and Flood Control of Jakarta, Jakarta Indonesia. Kementerian Pekerjaan Umum, Direktorat Jenderal Sumberdaya Air.

UPT Hujan Buatan - Badan Pengkajian dan Penerapan Teknologi. 2013. Laporan Kegiatan Pemanfaatan Teknologi Modifikasi Cuaca Untuk Redistribusi Curah Hujan Dalam Rangka Tanggap Darurat Banjir di Provinsi DKI Jakarta dan Sekitarnya Tahun 2013. UPT Hujan Buatan BPPT. Jakarta. 